Dynare Working Papers Series http://www.dynare.org/wp/

\title{
A Graphical Representation of an Estimated DSGE Model
}

\author{
Mariano Kulish \\ Callum Jones
}

Working Paper no. 3

May 2011

\footnotetext{
CE P R E M A P

CENTRE POUR LA RECHERCHE ECONOMIQUE ET SES APPLICATIONS

142, rue du Chevaleret - 75013 Paris — France http: //www . cepremap.ens.fr
} 


\title{
A Graphical Representation of an Estimated DSGE Model
}

\author{
Mariano Kulish and Callum Jones*
}

\begin{abstract}
We write a New Keynesian model as an aggregate demand curve and an aggregate supply curve, relating inflation to output growth. The graphical representation shows how structural shocks move aggregate demand and supply simultaneously. We estimate the curves on US data from 1948 to 2010. The Great Recession in 2008-09 is explained by a collapse of aggregate demand driven by adverse preference and permanent technology shocks, and expectations of low inflation.
\end{abstract}

JEL Codes: E27, E37, E58

${ }^{*}$ Economic Research Department, Reserve Bank of Australia. Mailing address: 65 Martin Place, Sydney, New South Wales, Australia, 2000. Email: kulishm at rba.gov.au and jonesc at rba.gov.au. 


\section{Introduction}

From month to month, discussions of monetary policy focus on understanding recent fluctuations in the data. Formal models contribute to this understanding to varying degrees across central banks. But as put by Alvarez-Lois et al. (2008), while there is a large literature that discusses the theory and estimation of DSGE models, there is relatively little that examines the communication of model results to policymakers. This issue is important and here we contribute to it by developing, for estimated DSGE models, a graphical representation, that because of its simplicity, helps formal models contribute even more to policy deliberations. The key innovation of the graphical analysis is that the action takes place in the space of observed variables, the space of inflation and output growth. The data is given but the model is not. What the graphical analysis reveals is how the underlying causes of movements from one quarter to the next decompose into aggregate demand and aggregate supply fluctuations.

In particular, we represent the New Keynesian model of Ireland (2004) graphically, characterising it in terms of an aggregate demand curve and aggregate supply curve. Each curve links inflation to output growth and a structural shift factor. The curves live in the observable space of output growth and inflation. This is not the first graphical representation of a dynamic macroeconomic model, but is, to the best of our knowledge, the first graphical representation of an estimated DSGE model. ${ }^{1}$ In recent work-that is independent to our own-Benigno (2009) develops a graphical representation of a two-period New Keynesian framework to illustrate, among other things, the impact of productivity and mark-up shocks and the role of fiscal multipliers. ${ }^{2}$ Although these graphical representations yield valuable insights, they cannot be taken to the data, either because they rely on unobservable quantities, like the output gap, or because they make strong simplifying assumptions, like a two-period economy.

The graphical analysis of the structural model yields insights that are likely to be novel to many. For example, the graphical representation makes it clear that any shock, be it a 'supply' shock or a 'demand' shock, shifts both the aggregate demand and aggregate supply curves through its impact on expectations. It also shows how increases in inflation expectations simultaneously

\footnotetext{
${ }^{1}$ Carlin and Soskice (2005) and King (2000) analyse different aspects of the New Keynesian model.

${ }^{2}$ Mankiw (2009) develops an ad-hoc graphical model of aggregate demand and supply.
} 
expand aggregate demand but contract aggregate supply. The degree to which inflation expectations exercise this joint influence depends crucially on the parameters that govern the slope of the curves: the degree of nominal rigidities, which governs the slope of the aggregate supply curve, and the parameters of the monetary policy rule, which, in turn, govern the slope of the aggregate demand curve.

As an application of the graphical representation, we show how the aggregate demand and aggregate supply curves behaved over the Great Recession of 2007 through 2009.

\section{The Graphical Representation}

The details of the New Keynesian model we use can be found in Ireland (2004). The eight linearized equations which characterise the economy's equilibrium are: ${ }^{3}$

$$
\begin{gathered}
\hat{x}_{t}=E_{t} \hat{x}_{t+1}-\left(\hat{r}_{t}-E_{t} \hat{\pi}_{t+1}\right)+(1-\omega)\left(1-\rho_{a}\right) \hat{a}_{t} \\
\pi_{t}=\pi+\beta E_{t} \hat{\pi}_{t+1}+\psi \hat{x}_{t}-\hat{e}_{t} \\
\hat{r}_{t}=\hat{r}_{t-1}+\rho_{\pi} \hat{\pi}_{t}+\rho_{g} \hat{g}_{t}+\rho_{x} \hat{x}_{t}+\varepsilon_{r, t} \\
\hat{x}_{t}=\hat{y}_{t}-\omega \hat{a}_{t} \\
g_{t}=g+\hat{y}_{t}-\hat{y}_{t-1}+\hat{z}_{t} \\
\hat{a}_{t}=\rho_{a} \hat{a}_{t-1}+\varepsilon_{a, t} \\
\hat{e}_{t}=\rho_{e} \hat{e}_{t-1}+\varepsilon_{e, t} \\
\hat{z}_{t}=\varepsilon_{z, t}
\end{gathered}
$$

where hat-variables represent deviations from steady state values with $\hat{y}_{t}$ denoting the deviation of detrended output from its steady-state, $\hat{x}_{t}$ the deviation of the output gap from its steady-state, $\hat{r}_{t}$ the deviation of the one-period interest rate from its steady-state, $\pi_{t}$ the one-period inflation rate,

\footnotetext{
${ }^{3}$ Detailed notes and MATLAB code accompanies Ireland's paper at http://www2.bc.edu/ irelandp/programs.html
} 
$a_{t}$ a preference shock, $e_{t}$ a negative cost-push shock and $z_{t}$ a total factor productivity shock which follows a random walk with drift. Note that output growth $g_{t}$ and inflation $\pi_{t}$ are expressed in levels.

The equations of the model can be manipulated to form aggregate supply and aggregate demand schedules relating inflation to output growth. To find the aggregate supply schedule, substitute Equations (4) and (5) into (2) to get:

$$
\pi_{t}=\psi g_{t}+\hat{s}_{t}+(\pi-\psi g)
$$

where $\hat{s}_{t}=\beta E_{t} \hat{\pi}_{t+1}+\psi \hat{y}_{t-1}-\psi \hat{z}_{t}-\omega \psi \hat{a}_{t}-\hat{e}_{t}$. In the space of output growth and inflation $\left(g_{t}, \pi_{t}\right)$, equation (9) expresses inflation as a linear function of output growth, with slope $\psi$ and intercept $\hat{s}_{t}+(\pi-\psi g)$. Note that the time-varying intercept $\hat{s}_{t}$ is zero when the economy is on its balanced growth path. Also note that the slope of the curve depends on the degree of nominal price rigidities. That is, as $\psi \rightarrow \infty$ prices become fully flexible which implies a vertical aggregate supply curve. Conversely as the cost of price adjustment rises, $\psi \rightarrow 0$, implying that the aggregate supply curve flattens.

To obtain the aggregate demand schedule, substitute Equations (3), (4) and (5) into (1) to get:

$$
\pi_{t}=-\left(\frac{1+\rho_{g}+\rho_{x}}{\rho_{\pi}}\right) g_{t}+\hat{d}_{t}+\left(\pi+\frac{1+\rho_{g}+\rho_{x}}{\rho_{\pi}} g\right)
$$

where $\hat{d}_{t}=-\frac{1}{\rho_{\pi}} \hat{r}_{t-1}+\frac{1}{\rho_{\pi}} E_{t} \hat{x}_{t+1}+\frac{1}{\rho_{\pi}} E_{t} \hat{\pi}_{t+1}-\left(\frac{1+\rho_{x}}{\rho_{\pi}}\right) \hat{y}_{t-1}+\left(\frac{1+\rho_{x}}{\rho_{\pi}}\right) \hat{z}_{t}+\frac{\omega\left(1+\rho_{x}\right)+(1-\omega)\left(1-\rho_{a}\right)}{\rho_{\pi}} \hat{a}_{t}-\frac{1}{\rho_{\pi}} \varepsilon_{r, t}$. Note that, as for the time-varying intercept in the aggregate supply curve, when the economy is on its balanced growth path, $\hat{d}_{t}$ is zero. The slope of the curve (10) depends on the parameters of the policy rule. A greater response to deviations of inflation from target, $\rho_{\pi}$, flattens the curve. Vice versa, stronger responses to output growth, $\rho_{g}$, and the output gap, $\rho_{x}$, steepen the aggregate demand curve.

With the values of $\hat{s}_{t}$ and $\hat{d}_{t}$ in hand, the aggregate supply curve (9) and the aggregate demand curve (10) can be written as a system of two equations in two variables $g_{t}$ and $\pi_{t}$. In matrix 
notation:

$$
\left[\begin{array}{cc}
1 & -\psi \\
1 & \frac{1+\rho_{g}+\rho_{x}}{\rho_{\pi}}
\end{array}\right]\left[\begin{array}{c}
\pi_{t} \\
g_{t}
\end{array}\right]=\left[\begin{array}{c}
\hat{s}_{t}+\pi-\psi g \\
\hat{d}_{t}+\pi+\left(\frac{1+\rho_{g}+\rho_{x}}{\rho_{\pi}}\right) g
\end{array}\right]
$$

The square matrix must be non-singular because the condition $\psi+\frac{1}{\rho_{\pi}}+\frac{\rho_{g}}{\rho_{\pi}}+\frac{\rho_{x}}{\rho_{\pi}} \neq 0$ is always satisfied for reasonable values of the policy parameters and $\psi>0$. Inverting the matrix, $\pi_{t}$ and $g_{t}$ can be solved by:

$$
\left[\begin{array}{c}
\pi_{t} \\
g_{t}
\end{array}\right]=\frac{1}{1+\rho_{g}+\psi \rho_{\pi}+\rho_{x}}\left[\begin{array}{c}
\pi\left(1+\rho_{x}+\rho_{g}+\psi \rho_{\pi}\right)+\psi \rho_{\pi} \hat{d}_{t}+\left(1+\rho_{g}+\rho_{x}\right) \hat{s}_{t} \\
g\left(1+\rho_{x}+\rho_{g}+\psi \rho_{\pi}\right)+\rho_{\pi} \hat{d}_{t}-\rho_{\pi} \hat{s}_{t}
\end{array}\right]
$$

At any point in time, the economy can be described in the output growth-inflation space, by the intersection of the aggregate supply curve, (9), and the aggregate demand curve (10). Figure 1 shows the $\left(g_{t}, \pi_{t}\right)$ space populated by quarterly US observations from 1948Q1 to 2010Q3. If drawn, the linear curves (9) and (10) would meet on these observations. But importantly, these observations are the same for every model.

We need estimates of the model parameters to generate the estimated aggregate demand and aggregate supply curves. We follow Ireland (2004) with updated data. We calibrate $\beta$ to $0.99, \psi$ to 0.1 , and $\omega$ to 0.06 . The remaining parameter estimates and standard errors are given in Table 1. They are much the same as Ireland's. Because of the strong estimated response of the short-rate to output growth and the output gap relative to the response to inflation, the slope of the aggregate demand curve is estimated to be steep: $-\frac{1+\rho_{g}+\rho_{x}}{\rho_{\pi}}=-4.4$. The aggregate supply curve is, owing to the low value of $\psi=0.1$, relatively flat. This explains why the model attributes an important role to aggregate demand shocks.

As noted, the evolution of the economy, in output growth-inflation space, can be described by the intersection of the aggregate supply and demand schedules at each point in time. A shock will shift the time-varying intercepts of the curves, $\hat{s}_{t}$ and $\hat{d}_{t}$. Over time, these curves move back toward the steady-state. So, for example, on the impact of a one standard deviation shock to $\varepsilon_{r, t}, \hat{s}_{t}=-0.001$ and $\hat{d}_{t}=-0.026$. Simultaneously, both curves move. To see this, return to the expression of the system in matrix notation (11) and substitute in the estimated parameter values 
to get:

$$
\left[\begin{array}{l}
\pi_{t} \\
g_{t}
\end{array}\right]=0.766\left[\begin{array}{c}
1.317+0.029 \hat{d}_{t}+1.277 \hat{s}_{t} \\
1.312+0.289 \hat{d}_{t}-0.289 \hat{s}_{t}
\end{array}\right]
$$

This illustrates an important feature of the analysis, that in general equilibrium, shocks simultaneously act on the shifting components of aggregate demand and aggregate supply, $\hat{d}_{t}$ and $\hat{s}_{t}$, through the expectations channel. In the case of the monetary policy shock, in the period of the shock, the increase in $\hat{r}_{t}$ directly leads to a contraction in aggregate demand as agents adjust consumption. Simultaneously, agents expect the output gap to be negative in the next period and inflation to be below steady-state which, through the Euler condition, contracts aggregate demand further. For the supply side, a fall in inflation expectations acts to expand supply: because it is costly for firms to adjust prices, they have an incentive, for any given level of output, to reduce prices today.

We illustrate the curves and their dynamics following a monetary policy shock in output growthinflation space. Figure 2 draws the aggregate demand and aggregate supply curves at steady-state, the period of the monetary policy shock $t=1$, and four periods later at $t=5$. It shows the contraction in aggregate demand and the expansion in aggregate supply from steady-state following the shock, and the movements in the curves as the economy returns to steady-state.

\section{The Great Recession}

We estimated the model on US data from 1948Q1 to 2010Q3. This allows us to analyse the behaviour of aggregate demand and aggregate supply over the period of the Great Recession (Ireland, 2011). As per Ireland (2004), the observed quarterly series were the growth rate in US GDP per person, inflation of the US GDP deflator and the 3-month Treasury bill rate. The advantage of drawing the curves in output growth-inflation space is that the analysis is done relative to fixed and observable points and that through estimation we can understand the forces moving the aggregate demand and aggregate supply curves from the observed points.

We focus on the more recent period of estimation. Figure 3 gives the position of the US economy for each quarter from 1990Q1 to 2010Q3, with the quarters from 2007Q1 highlighted in black. The 
aggregate demand and supply curves are drawn for 2007Q2, and for 2008Q4 when the curves were farthest from the steady-state. The dashed lines can be followed to give the path of the economy over this period.

The figure makes it clear the extent of the recessionary forces on the US economy in late 2008, with both inflation and output growth falling well below steady-state. At the estimated parameter values, the shift of the economy from early 2007 to late 2008 reflected a large decline in aggregate demand and a significant increase in aggregate supply, as illustrated by the relative positions of the curves. Following the trough in 2008Q4, aggregate demand was estimated to recover to above its steady-state position by 2009Q4, while aggregate supply remained away from steady-state.

To understand why these curves moved, Table 2 shows the components of aggregate demand and aggregate supply as per Equations (9) and (10). A few observations are notable. Over the period, expected inflation below steady-state inflation held back demand which, according to the model, led households to hold back consumption. Further, a sequence of relatively large negative preference shocks and negative permanent technology shocks, also restrained aggregate demand. On the aggregate supply curve, expected inflation below steady-state in 2008Q4 accounts for much of the movement in the supply curve from 2008Q3. A series of estimated positive cost push shocks also pushed the aggregate supply curve down: a positive cost push shock temporarily increases the elasticity of demand for firms' output and reduces their markup over marginal costs, decreasing prices.

The graphical analysis highlights the importance of $\psi$, the degree of nominal rigidities, in interpreting the data. If we were to set this parameter differently and re-estimate the model, we would find, not surprisingly, different shocks that match the data. This seems clear enough, but is emphasised by observing that in Figure 3, the data points are fixed. Different parameter values would change the slopes of the two curves. As such, different shocks will be needed to move those curves from observation to observation, that is, the contents of Table 2 will change. For example, if we instead calibrate a steep aggregate supply curve, the interpretation of the movement in aggregate supply in moving from 2007Q1 to 2008Q4 is different. In Figure 3(b), $\psi$ is calibrated to be equal to 0.9 , which steepens the aggregate supply curve. With this calibration, the interpretation of the movement in aggregate supply from 2007Q2 to 2008Q4 is reversed: aggregate supply contracted. 
Much of difference is due to the magnitude of the estimated technology and preference shocks outweighing the expansionary effect of falling inflation expectations. ${ }^{4}$

\section{References}

Pedro Alvarez-Lois, Richard Harrison, Laura Piscitelli, and Alasdair Scott. On the Application and Use of DSGE Models. Journal of Economic Dynamics and Control, 32:2428-2452, 2008.

Pierpaolo Benigno. New Keynesian Economics: An AS-AD View. Working Paper 14824, National Bureau of Economic Research, 2009.

Wendy Carlin and David Soskice. The 3-Equation New Keynesian Model - A Graphical Exposition. Contributions to Macroeconomics, 5(1):Article 13, 2005.

Peter N Ireland. Technology Shocks in the New Keynesian Model. The Review of Economics and Statistics, 86(4):923-936, 2004.

Peter N Ireland. A New Keynesian Perspective on the Great Recession. Journal of Money, Credit and Banking, 43(1):31-54, 2011.

Robert G King. The New IS-LM Model: Language, Logic, and Limits. Federal Reserve Bank of Richmond Economic Quarterly, 86(3):45-103, 2000.

Greg Mankiw. Macroeconomics, chapter 14, A Dynamic Model of Aggregate Demand and Aggregate Supply. Worth Publishers, 2009.

\footnotetext{
${ }^{4}$ Our MATLAB files are available on request.
} 
Figure 1: United States, 1948Q1-2010Q3

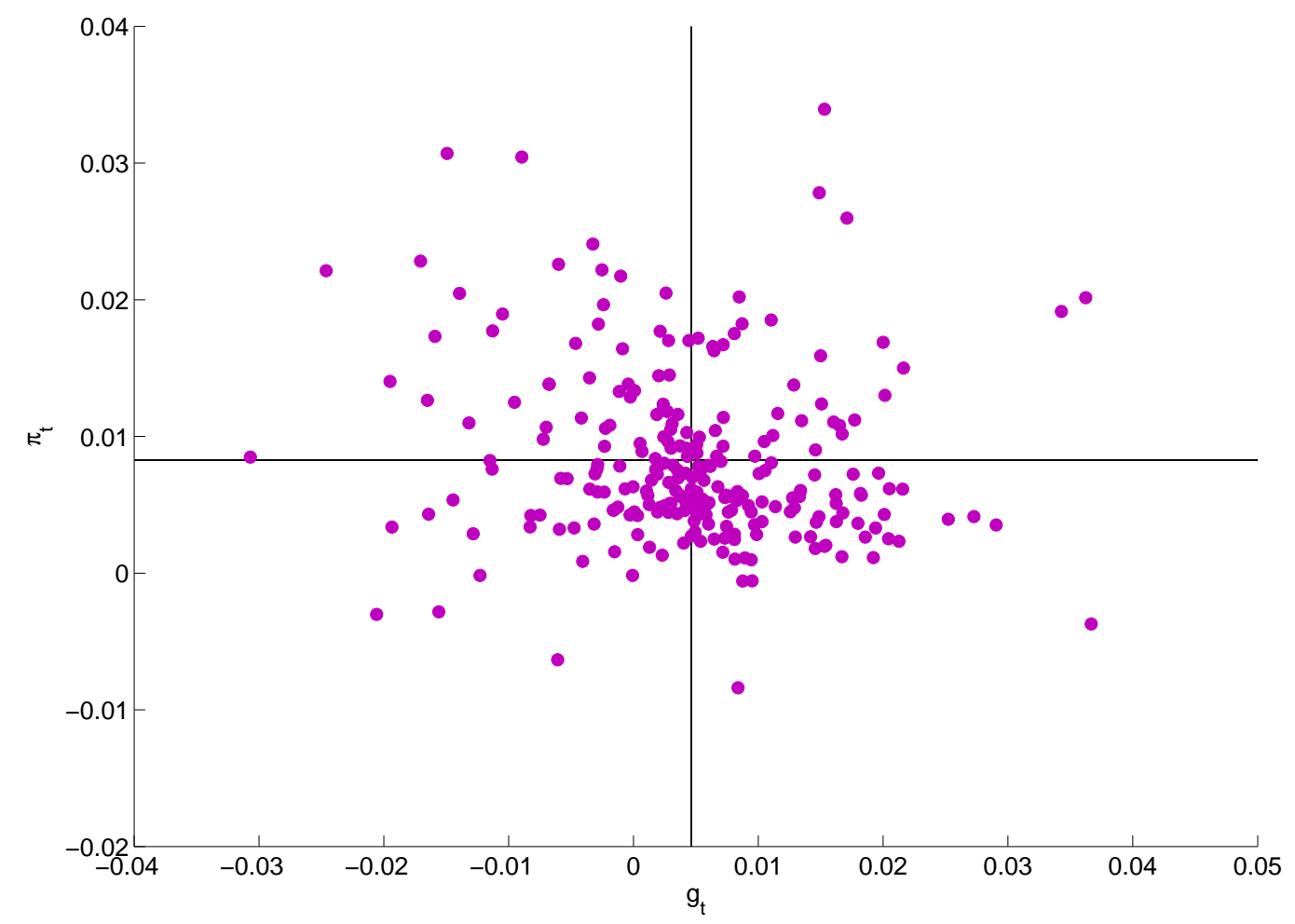

Table 1: Maximum Likelihood Estimates

\begin{tabular}{|c|c|c|}
\hline Parameter & Estimate & Standard Error \\
\hline \hline$\rho_{a}$ & 0.9489 & 0.0224 \\
$\rho_{e}$ & 0.9470 & 0.0393 \\
$\rho_{\pi}$ & 0.2885 & 0.0404 \\
$\rho_{g}$ & 0.2090 & 0.0451 \\
$\rho_{x}$ & 0.0679 & 0.0177 \\
$\sigma_{a}$ & 0.0365 & 0.0122 \\
$\sigma_{e}$ & 0.0008 & 0.0002 \\
$\sigma_{z}$ & 0.0120 & 0.0015 \\
$\sigma_{r}$ & 0.0026 & 0.0003 \\
\hline
\end{tabular}


Figure 2: Aggregate Demand and Aggregate Supply Curves: $\varepsilon_{r}$ Shock

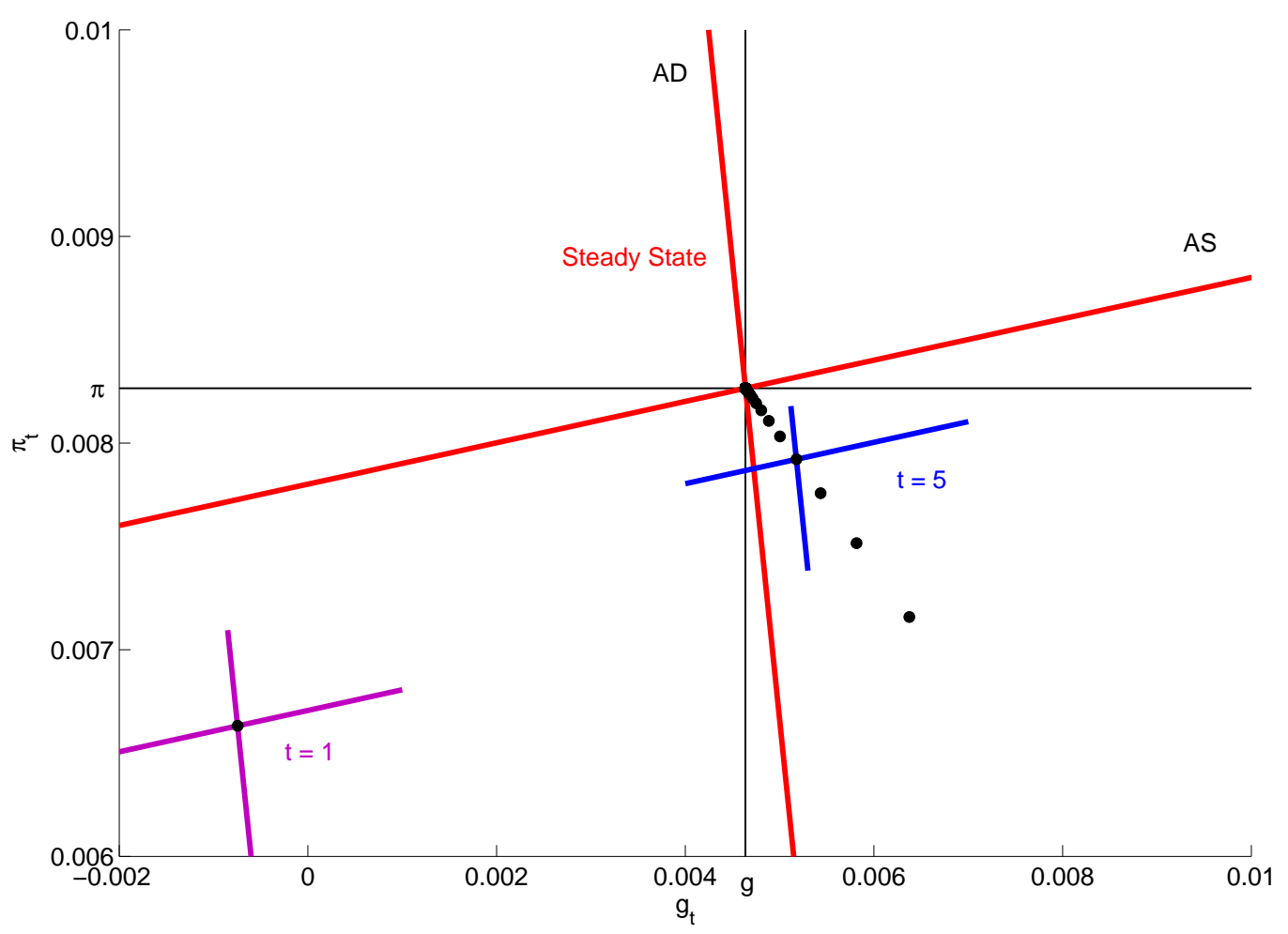

Table 2: Decomposition of US Aggregate Demand and Aggregate Supply, 2008Q1-2009Q4

\begin{tabular}{|c|r|r|r|r|r|r|r|r|r|}
\hline & 2008Q1 & 2008Q2 & 2008Q3 & \multicolumn{1}{|c|}{ 2008Q4 } & 2009Q1 & 2009Q2 & 2009Q3 & 2009Q4 \\
\hline \hline Component & \multicolumn{7}{|c|}{ Aggregate Demand } \\
\hline$\hat{d}_{t}$ & -0.0295 & -0.0258 & -0.0761 & -0.1228 & -0.0827 & -0.0460 & -0.0212 & 0.0127 \\
$\frac{1}{\rho_{\pi}} E_{t} \hat{x}_{t+1}$ & 0.0818 & 0.0981 & 0.1008 & 0.0863 & 0.0889 & 0.0807 & 0.0796 & 0.0802 \\
$\frac{1}{\rho_{\pi}} E_{t} \hat{\pi}_{t+1}$ & -0.0115 & -0.0042 & 0.0040 & -0.0317 & -0.0164 & -0.0214 & -0.0186 & -0.0250 \\
$-\left(\frac{1+\rho_{x}}{\rho_{\pi}}\right) \hat{y}_{t-1}$ & -0.0500 & -0.0854 & -0.1119 & -0.1211 & -0.0510 & -0.0667 & -0.0487 & -0.0491 \\
$-\frac{1}{\rho_{\pi}} \hat{r}_{t-1}$ & 0.0105 & 0.0221 & 0.0257 & 0.0269 & 0.0372 & 0.0379 & 0.0383 & 0.0384 \\
$\left(\frac{1+\rho_{x}}{\rho_{\pi}} \hat{z}_{t}\right.$ & -0.0572 & -0.0477 & -0.0751 & -0.0232 & -0.0804 & -0.0142 & -0.0129 & 0.0239 \\
$\frac{\omega\left(1+\rho_{x}\right)+(1-\omega)\left(1-\rho_{a}\right)}{\rho_{\pi}} \hat{a}_{t}$ & -0.0130 & -0.0154 & -0.0190 & -0.0458 & -0.0499 & -0.0540 & -0.0554 & -0.0560 \\
$-\frac{1}{\rho_{\pi}} \varepsilon_{r, t}$ & 0.0098 & 0.0066 & -0.0006 & -0.0143 & -0.0112 & -0.0083 & -0.0036 & 0.0004 \\
\hline Component & \multicolumn{7}{|c|}{ Aggregate Supply } & & \\
\hline$\hat{s}_{t}$ & -0.0028 & 0.0001 & 0.0045 & -0.0088 & -0.0036 & -0.0065 & -0.0060 & -0.0093 \\
$\beta E_{t} \hat{\pi}_{t+1}$ & -0.0033 & -0.0012 & 0.0011 & -0.0091 & -0.0047 & -0.0061 & -0.0053 & -0.0071 \\
$\psi \hat{y}_{t-1}$ & 0.0014 & 0.0023 & 0.0030 & 0.0033 & 0.0014 & 0.0018 & 0.0013 & 0.0013 \\
$-\psi \hat{z}_{t}$ & 0.0015 & 0.0013 & 0.0020 & 0.0006 & 0.0022 & 0.0004 & 0.0003 & -0.0006 \\
$-\omega \psi \hat{a}_{t}$ & 0.0002 & 0.0002 & 0.0003 & 0.0007 & 0.0008 & 0.0008 & 0.0009 & 0.0009 \\
$-\hat{e}_{t}$ & -0.0027 & -0.0025 & -0.0020 & -0.0043 & -0.0033 & -0.0035 & -0.0033 & -0.0037 \\
\hline
\end{tabular}


Figure 3: United States, 1990Q1-2010Q3

(a) $\psi=0.1$

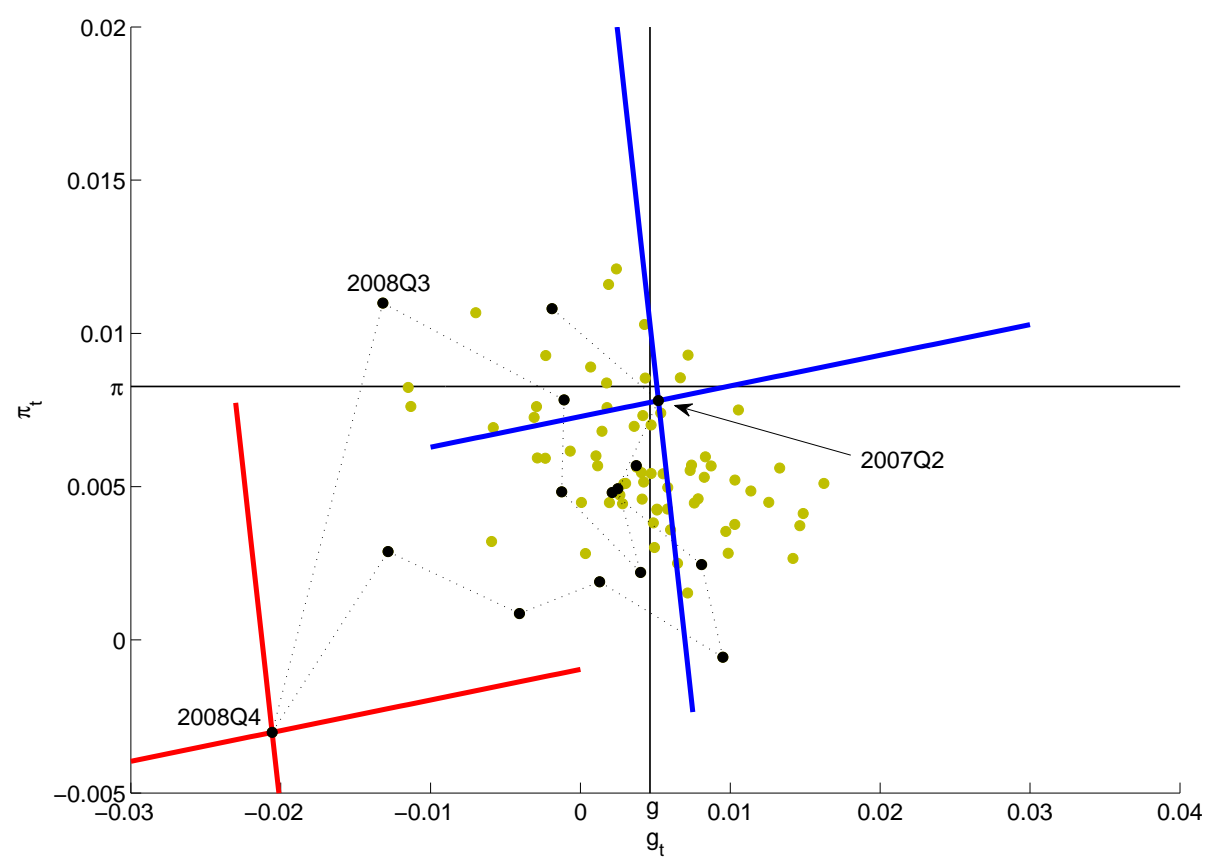

(b) $\psi=0.9$

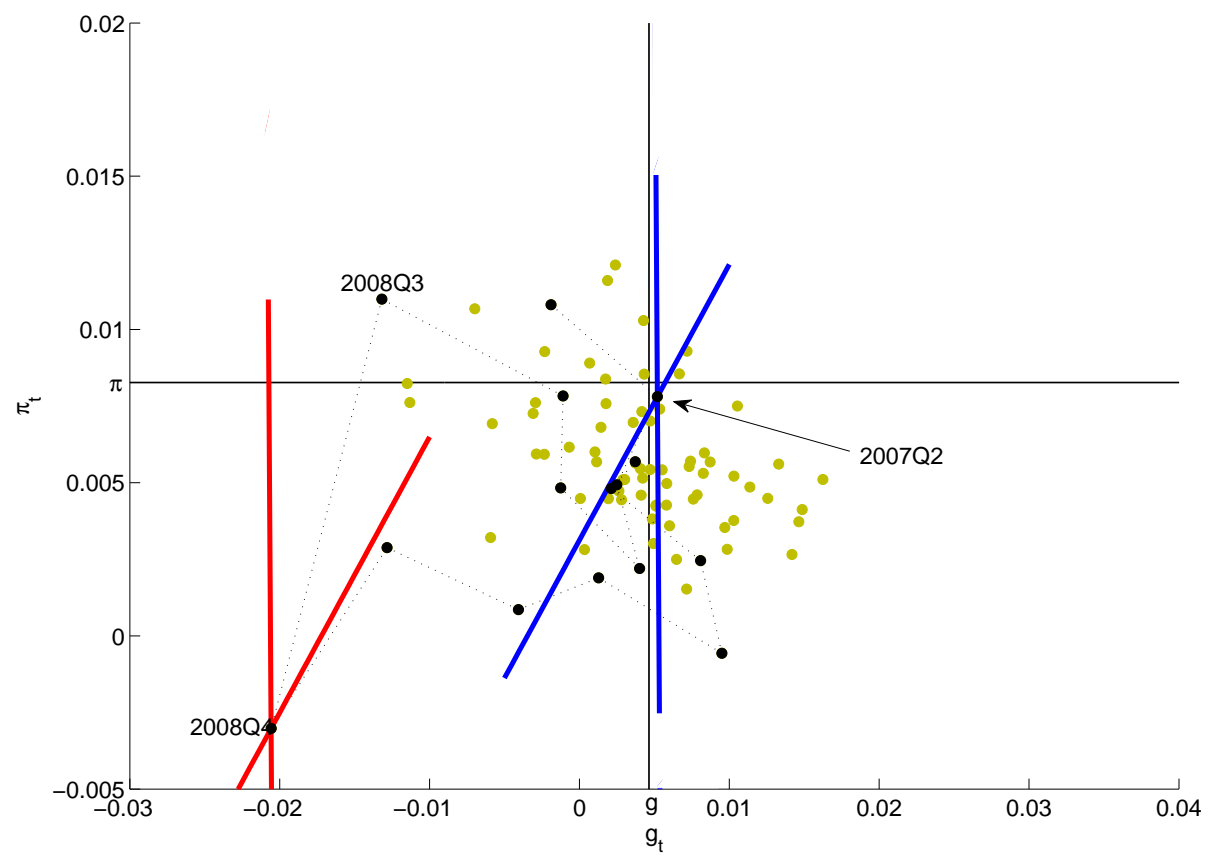

